Pacific Journal of Mathematics

GENERALIZATION OF A THEOREM OF LANDAU 


\section{GENERALIZATION OF A THEOREM OF LANDAU}

\section{Miriam HaUSMaN}

\section{A well known theorem of Landau asserts that}

$$
\varliminf_{n \rightarrow \infty} \frac{\phi(n) \log \log n}{n}=e^{-r}
$$

where $\gamma=$ Euler's constant. In this paper a generalization is obtained by focusing on

$$
G(k)=\varliminf_{n \rightarrow \infty}(\log \log n)^{1 / k} \max \left(\frac{\phi(n+1)}{n+1}, \cdots, \frac{\phi(n+k)}{n+1}\right) .
$$

Clearly, the assertion $G(1)=e^{-\gamma}$ is precisely Landau's theorem. It is proved that

$$
G(k)=e^{-\gamma / k} \prod_{p<k}\left(1-\frac{1}{p}\right)^{-1 / k} \psi(k)
$$

where

$$
\psi(k)=\prod_{\substack{p \nmid k \\ p<k}}\left(1-\frac{1}{p}\right)^{1 / p} \prod_{\substack{p \nmid k \\ p<k}}\left(1-\frac{1}{p}\right)^{(1 / k)[k / p]+1 / k} .
$$

The function $\psi(k)$ satisfies $0<\psi(k) \leqq 1$ and it is easily seen from (1.4) that

$$
\lim _{k \rightarrow \infty} \psi(k)=\prod_{p}\left(1-\frac{1}{p}\right)^{1 / p}
$$

2. Preliminary lemmas. The results obtained in this paper depend on the following well known theorems [1], [2], and [3].

$$
\begin{aligned}
& \lim _{n \rightarrow \infty} \frac{\phi(n) \log \log n}{n}=e^{-r} \quad \text { (Landau's theorem) } \\
& \sum_{p \leqq x} \frac{1}{p}=\log \log x+c+O\left(\frac{1}{\log x}\right) \quad \text { (Mertens') } \\
& \prod_{p \leqq x}\left(1-\frac{1}{p}\right)=\frac{e^{-r}}{\log x}+O\left(\frac{1}{\log ^{2} x}\right) \quad \text { (Mertens') }
\end{aligned}
$$

3. Proof of (1.3). We introduce

$$
\left(\frac{\dot{\phi}(n)}{n}\right)_{k}=\prod_{\substack{p ; n \\ p \geq k}}\left(1-\frac{1}{p}\right)
$$

and

$$
f_{k}(n)=\prod_{\substack{p \nmid n \\ p<k}}\left(1-\frac{1}{p}\right)
$$


and note that $f_{k}(n)$ is periodic with period $\Delta_{k}=\prod_{p<k} p$.

We also observe that (1.2) is clearly equivalent to

(3.3) $G(k)=\min _{1 \leqq J \leqq \Delta_{k}} \lim _{\substack{n \rightarrow \infty \\ n \equiv J\left(\bmod { }_{k}\right)}}(\log \log n)^{1 / k} \max \left(\frac{\phi(n+1)}{n+1}, \cdots, \frac{\phi(n+k)}{n+k}\right)$.

On the sequence $n \equiv J\left(\bmod \Delta_{k}\right)$

$$
(\log \log n) \prod_{i=1}^{k} \frac{\phi(n+i)}{n+i}=(\log \log n) \prod_{i=1}^{k}\left(\frac{\phi(n+i)}{n+i}\right)_{k} f_{k}(J+i) .
$$

Since a prime $p$ divides $n+i$ and $n+j$ only if $p$ divides $i-j$, $1 \leqq j<i \leqq k$; and the primes involved in $(\phi(n) / n)_{k}$ are $p \geqq k$, we have

$$
\prod_{i=1}^{k}\left(\frac{\dot{\phi}(n+i)}{n+i}\right)_{k}=\left(\frac{\phi\left[\prod_{i=1}^{k}(n+i)\right]}{\prod_{i=1}^{k}(n+i)}\right)_{k} .
$$

This together with the result

$$
\varliminf_{n \rightarrow \infty}(\log \log n)\left(\frac{\phi(n)}{n}\right)_{k}=e^{-r} \prod_{p<k}\left(1-\frac{1}{p}\right)^{-1}
$$

(which follows from Landau's theorem) yields

$$
(\log \log \mathrm{n}) \prod_{i=1}^{k}\left[\frac{\phi(n+i)}{n+i}\right] \geqq(1+o(1)) e^{-r} \prod_{p<k}\left(1-\frac{1}{p}\right)^{-1} \prod_{i=1}^{k} f_{k}(J+i),
$$

which implies

$$
\begin{aligned}
& \lim _{\substack{\left.n \rightarrow \infty \\
n \equiv J^{\prime \rightarrow \infty} \bmod { }_{k}\right)}}(\log \log n)^{1 / k} \max _{i=1, \cdots, k}\left(\frac{\phi(n+i)}{n+i}\right) \\
& \geqq e^{-\gamma / l} \prod_{p<k}\left(1-\frac{1}{p}\right)^{-1 / k}\left[\prod_{i=1}^{k} f_{k}(J+i)\right]^{1 / k} .
\end{aligned}
$$

In (3.5), taking the minimum over $J, 1 \leqq J \leqq \Delta_{k}$, and using (3.3) yields

$$
G\left(l_{i}\right) \geqq e^{-\gamma / k} \prod_{p<k}\left(1-\frac{1}{p}\right)^{-1 / k}\left[\min _{1 \leqq J \leqq} \prod_{i=1}^{k} f_{k}(J+i)\right]^{1 / k} .
$$

Choose $J^{*}$ such that

$$
\left[\min _{1 \leqq J \leqq \Delta_{k}} \prod_{i=1}^{k} f_{k}(J+i)\right]^{1 / k}=\left[\prod_{i=1}^{k} f_{k}\left(J^{*}+i\right)\right]^{1 / k} .
$$

We next observe that for the $f(k)$ given in (1.4) we have

$$
\left[\prod_{i=1}^{k} f_{k}\left(J^{*}+i\right)\right]^{1 / k}=\psi(k) \text {. }
$$

To see this note first that the left side of (3.7) equals 


$$
\min _{1 \leqq J \leqq d_{k}}\left[\prod_{\substack{p \mid J+1 \\ p<k}}\left(1-\frac{1}{p}\right) \prod_{\substack{p \mid J+2 \\ p<k}}\left(1-\frac{1}{p}\right) \cdots \prod_{\substack{p \mid J+k \\ p<k}}\left(1-\frac{1}{p}\right)\right]^{1 / k} .
$$

Since each of the factors $(1-1 / p)<1$, the minimum of the product in (3.8) is achieved for that value of $J$ for which each prime $p<k$ divides as many of the $k$ integers $J+1, \cdots, J+k$ as possible. Since $p<k, k=p t+r, t=[k / p], 0 \leqq r<p$. If $r=0$, i.e., $p \mid k$, then the $k$ integers $J+1, \cdots, J+k$ can be broken up into exactly $t$ complete residue systems modulo $p$ and in each system we have one integer $\equiv$ $0(\bmod p)$; this situation is independent of the choice of $J$. If $r>0$ then the $k$ integers $J+1, \cdots, J+k$ form $t$ complete residue classes modulo $p$ together with $r<p$ remaining integers. In each of the complete residue classes there is one integer $\equiv 0(\bmod p)$. We would like to show that it can be arranged that for each $p<k, p \nmid k$, one of the $r$ remaining integers is $\equiv 0(\bmod p)$, and thus we have $[k / p]+1$ integers divisible by $p$. Since $1 \leqq J \leqq \Delta_{k}$ where $\Delta_{k}=\Pi_{p<k} p$, we can choose $J=\Delta_{k}-1$; then every $p<k$ divides $J+1$. Hence for $p \nmid k$, the $[k / p]+1$ integers $J+1+\tau p, 0 \leqq \tau \leqq t$ are divisible by $p$ as desired, and (3.7) follows.

From (3.6) and (3.7) we see that

$$
G(k) \geqq e^{-\gamma / k} \prod_{p<k}\left(1-\frac{1}{p}\right)^{-1 / k} \psi(k) ;
$$

and it remains to prove the reverse inequality. This is achieved by showing that there exists an infinite sequence $n \equiv J^{*}\left(\bmod \Delta_{k}\right)$ on which

$$
\begin{gathered}
\lim _{\substack{\left.n \rightarrow \infty \\
n \equiv J *(\bmod \lrcorner_{k}\right)}}(\log \log n)^{1 / k} \max _{i=1, \cdots, k}\left(\frac{\phi(n+i)}{n+i}\right) \\
\leqq e^{-\gamma / k} \prod_{p<k}\left(1-\frac{1}{p}\right)^{-1 / k} \psi(k) .
\end{gathered}
$$

This is done by producing a sequence $n \equiv J^{*}\left(\bmod \Delta_{k}\right)$ for which

$$
(\log \log n)^{1 / k} \max _{i=1, \cdots, k}\left(\frac{\phi(n+i)}{n+i}\right)_{k} \sim e^{-\gamma / k} \prod_{p<k}\left(1-\frac{1}{p}\right)^{-1 / k} \lambda_{i}
$$

where for all $i=1, \cdots, k$,

$$
\lambda_{i}=\frac{\psi(k)}{f_{k}\left(J^{*}+i\right)}
$$

On this sequence

$$
(\log \log n)^{1 / k} \max _{i=1, \cdots, k}\left(\frac{\phi(n+i)}{n+i}\right) \sim e^{-\gamma / k} \prod_{p<k}\left(1-\frac{1}{p}\right)^{-1 / k} \max _{i=1, \cdots, k}\left(\lambda_{i} f_{k}\left(J^{*}+i\right)\right)
$$




$$
\sim e^{-i / k} \prod_{p<k}\left(1-\frac{1}{p}\right)^{-1 / k} i(k),
$$

which gives the reverse inequality to (3.9) and establishes (1.3).

To construct the sequence $n \equiv J^{*}\left(\bmod A_{k}\right)$ which satisfies $(3.8)$ let

$$
\begin{aligned}
& B_{1}=\prod_{k \leq p<\exp \left(c_{1} \log x\right)} p, \\
& B_{i}=\prod_{\exp \left(\left(c_{i-1}\right)(\log x)^{i-1}\right) \leq p<\exp \left(c_{i}(\log x)^{i}\right)} p, \quad i=2, \cdots, k ;
\end{aligned}
$$

where $c_{k}=1$, and for $i=0, \cdots, k-1, c_{i}$ is determined by

$$
\frac{c_{i-1}}{c_{i}}=e^{-\gamma / k} \prod_{p<k}\left(1-\frac{1}{p}\right)^{-1 / k} \lambda_{i} .
$$

Since $\prod_{i=1}^{k} \lambda_{i}=1$ it follows that $c_{0}=e^{-\gamma} \prod_{p<k}(1-1 / p)$. As the $B_{i}$, $i=1, \cdots, k$ are $k$ integers made up of primes $p \geqq k$ and are relatively prime in pairs, as well as each relatively prime to $\Delta_{k}$, by the Chinese Remainder Theorem the system

$$
\begin{gathered}
y+1 \equiv O\left(\bmod B_{1}\right) \\
y+2 \equiv O\left(\bmod B_{2}\right) \\
\vdots \\
y+k \equiv O\left(\bmod B_{k}\right) \\
y \equiv J^{*}\left(\bmod \Delta_{k}\right)
\end{gathered}
$$

has a solution $y=n^{*}, 0<n^{*}<\Delta_{k} \prod_{i=1}^{k} B_{i}$ which is unique modulo $\Delta_{k} \prod_{i=1}^{k} B_{i}$.

For this integer $n^{*} \equiv J^{*}\left(\bmod \Delta_{k}\right)$ we have for $i=1, \cdots, k$

$$
\begin{gathered}
\left(\frac{\dot{\phi}\left(n^{*}+i\right)}{n^{*}+i}\right)_{k}=\prod_{\substack{p ; n^{*}+i \\
p \geqq k}}\left(1-\frac{1}{p}\right) \leqq \prod_{p: b_{i}}\left(1-\frac{1}{p}\right) \\
\leqq \frac{c_{i-1}}{c_{i}}\left(\frac{1}{\log x}\right)+O\left(\frac{1}{\log ^{2} x}\right),
\end{gathered}
$$

(note that the value obtained for $c_{0}$ validates this for $i=1$ ). Then

$$
\begin{aligned}
& \left(\frac{\dot{\phi}\left(n^{*}+i\right)}{n^{*}+i}\right)_{k} f_{k}\left(J^{*}+i\right) \\
& \leqq \frac{\lambda_{i} e^{-\gamma / k} \prod_{p<k}\left(1-\frac{1}{p}\right)^{-1 / k}}{\log x} f_{l}\left(J^{*}+i\right)(1+o(1)) .
\end{aligned}
$$

But from the Prime Number Theorem since

$$
n^{*}<\Delta_{k} \prod_{i=1}^{k} B_{i}=\prod_{p<\exp \left\{[\log x\}_{k} k^{2}\right.} p, \quad\left(c_{k}=1\right),
$$


it follows that

$$
\log n^{*} \leqq \sum_{p<a x p\{\log x\} k} \log p=O\left(e^{(\log x\} k}\right)
$$

so that

$$
\log \log n^{*} \leqq(\log x)^{k}+O(1)
$$

Since (3.14) holds for all $i=1, \cdots, k$, it certainly holds for the maximum of these functions. Thus inserting (3.15) in (3.14) yields

$$
\begin{gathered}
\left(\log \log n^{*}\right)^{1 / k} \max _{i=1, \cdots, k}\left(\frac{\phi\left(n^{*}+i\right)}{n^{*}+i}\right)_{k} f_{k}\left(J^{*}+i\right) \\
\leqq(1+o(1)) e^{-\gamma / k} \prod_{p<k}\left(1-\frac{1}{p}\right)^{1 / k} \psi(k) .
\end{gathered}
$$

Clearly as $x$ tends to infinity the $n^{*}$ (which depends on $x$ ) also tends to infinity, so that (3.16) yields

$$
G(k) \leqq e^{-\gamma / k} \prod_{p \backslash k}\left(1-\frac{1}{p}\right)^{-1 / k} \dot{\psi}(k)
$$

which completes the proof of (1.3).

\section{REFERENCES}

1. G. H. Hardy and E. M. Wright, An Introduction to the Theory of Numbers, Oxford University Press, (1968), 349-354.

2. E. Landau, Über den Verlauf der zahlentheoretischen Funktion $\phi(x)$, Archiv der Mathematik und Physik, (3) 5 (1903), 86-91.

3. F. Mertens, Ein Beitrag zur analytischen Zahlentheorie, Journal für die reine und angewandte Mathematik, Bd. 78 (1874), 46-62.

Received January 27, 1977 and in revised form March 8, 1979.

BARUCH COLlege

CUNY

NEW YoRK, NY 10010 



\section{PACIFIC JOURNAL OF MATHEMATICS}

\section{EDITORS}

DONALD BABBITT (Managing Editor)

University of California

Los Angeles, California 90024

Hugo RossI

University of Utah

Salt Lake City, UT 84112

C. C. MOORE and ANDrew OGG

University of California

Berkeley, CA 94720
J. DUgundjI

Department of Mathematics University of Southern California Los Angeles, California 90007

R. FinN aNd J. Milgram Stanford University Stanford, California 94305

\section{ASSOCIATE EDITORS}

E. F. BECKENBACH

B. H. NeUMANN

F. WOLF

K. YosHIDA

\section{SUPPORTING INSTITUTIONS}

UNIVERSITY OF BRITISH COLUMBIA CALIFORNIA INSTITUTE OF TECHNOLOGY UNIVERSITY OF CALIFORNIA MONTANA STATE UNIVERSITY UNIVERSITY OF NEVADA, RENO NEW MEXICO STATE UNIVERSITY OREGON STATE UNIVERSITY UNIVERSITY OF OREGON
UNIVERSITY OF SOUTHERN CALIFORNIA STANFORD UNIVERSITY UNIVERSITY OF HAWAII UNIVERSITY OF TOKYO UNIVERSITY OF UTAH WASHINGTON STATE UNIVERSITY UNIVERSITY OF WASHINGTON 


\section{Pacific Journal of Mathematics}

\section{Vol. 84 , No. 1 \\ May, 1979}

Michael James Beeson, Goodman's theorem and beyond ...............

Robert S. Cahn and Michael E. Taylor, Asymptotic behavior of multiplicities

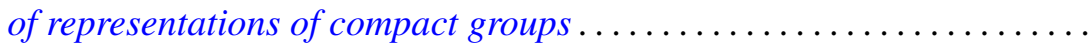

Douglas Michael Campbell and Vikramaditya Singh, Valence properties of

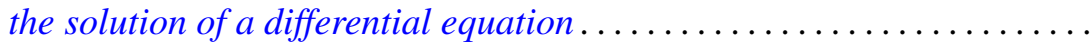

J.-F. Colombeau, Reinhold Meise and Bernard Perrot, A density result in spaces of Silva holomorphic mappings .....................

Marcel Erné, On the relativization of chain topologies .................

Le Baron O. Ferguson, Uniform and $L_{p}$ approximation for generalized

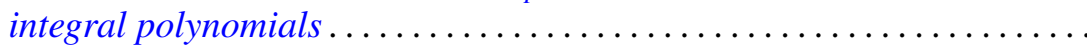

Kenneth R. Goodearl and David E. Handelman, Homogenization of regular rings of bounded index..................................

Friedrich Haslinger, A dual relationship between generalized

Abel-Gončarov bases and certain Pincherle bases .................

Miriam Hausman, Generalization of a theorem of Landau. .

Makoto Hayashi, 2-factorization in finite groups

Robert Marcus, Stochastic diffusion on an unbounded domain ........... 143

Isabel Dotti de Miatello, Extension of actions on Stiefel manifolds....

C. David (Carl) Minda, The hyperbolic metric and coverings of Riemann surfaces...

Somashekhar Amrith Naimpally and Mohan Lal Tikoo, On $T_{1}$-compactifications.

Chia-Ven Pao, Asymptotic stability and nonexistence of global solution for a semilinear parabolic equation ....

Shigeo Segawa, Harmonic majoration of quasibounded type ...

Sze-Kai Tsui and Steve Wright, The splitting of operator algebras ...

Bruce Williams, Hopf invariants, localization and embeddings of Poincaré complexes....

Leslie Wilson, Nonopenness of the set of Thom-Boardman maps ...

Alicia B. Winslow, There are $2^{\mathrm{c}}$ nonhomeomorphic continua in $\beta R^{n}-R^{n}$ 